
B ulletin of
$\mathbf{M}$ anagement \&
B usiness
ISSN-p:
ISSN-e:
DOI:

\title{
Pemasaran Pariwisata Berbasis Edukasi Kota Malang
}

\section{Rini Safitri ${ }^{1}$}

\begin{abstract}
Abstrak
Penelitian ini mendeskripsikan fenomena sejarah Museum Brawijaya Malang. Penelitian ini menggunakan metode kualitatif literatur. Setting Penelitian berada di Museum Brawijaya Malang. Pengumpulan data diperoleh dari dokumentasi dan sumbersumber tertulis baik tercetak maupun elektronik.

Hasil penelitian menunjukkan bahwa pariwisata berbasis edukasi sejarah sangatlah penting bagi masyarakat khususnya generasi-generasi muda atau generasi milenial agar dapat memiliki nilai-nilai kejuangan suatu bangsa.

Keterbatasan/Implikasi pada penelitian adalah perlunya pengembangan promosi di media sosial agar dikenal luas oleh masyarakat, baik di nasional maupun internasional.
\end{abstract}

Kata Kunci: Pemasaran Pariwisata, Base Oriented Social Marketing

\section{Abstract}

This study describes the historical phenomenon of Malang Brawijaya Museum. This study uses a qualitative literature method. The research setting is in Malang Brawijaya Museum. Data collection was obtained from written and electronic documentation and written sources.

The result show what is meant by educational which is important for the community of young generation or millennial generation so that they can have victory values for the nation.

Limitation / Implications for research are the need to develop promotion on social media so that it is widely known by the public, both nationally and internationally.

Keyword: Tourism Marketing, Base Oriented Social Marketing

\footnotetext{
${ }^{1}$ Fakultas Ekonomi, UIN Maulana Malik Ibrahim, Malang, rinisafitriiksan@gmail.com
} 


\section{PENDAHULUAN}

Kota Malang merupakan kota yang memiliki gelar Kota Pendidikan dan Kota Sejarah. Salah satu, keunikkan di Kota malang adalah Museum Brawijaya (Thamrin, 2013).

Museum Brawijaya merupakan wisata yang berbasis edukasi sejarah yang menyimpan benda-benda koleksi bersejarah (Bintaldam, 2008). Pendirian Museum Brawijaya adalah untuk dapat mengedukasikan kepada masyarakat perjuangan bangsa Indonesia sejak 1945 dan untuk membuktikan dharma bhaktinya kepada ibu pertiwi (Bintaldam, 2008).

Mengenalkan Museum Brawijaya kepada masyarakat tidaklepas dari konsep pemasaran pariwisata. Pentingnya pemasaran pariwisata, yaitu peningkatan pemahaman pada hakikat produk pariwisata, perkembangan pasar yang sangat dinamik menuntut strategi pemasaran yang cerdas dan bertanggung jawab kepada wisatawan, perubahan tren pemasaran global, dan otonomi daerah (Hasan, 2015).

Konsep pemasaran pariwisata mengusung tema Pemasaran sosial. Pemasaran sosial adalah pemasaran yang beorientasi pada sosial yang menentukan keinginan seseorang untuk mencapai kepuasan tersendiri melalui edukasi yang berdampak dalam jangka panjang (Hasan, 2015).

Tujuan dari studi kepustakaan ini adalah untuk menjelaskan dan mendeskripsikan wisata berbasis edukasi sejarah di Museum Brawijaya.

\section{KAJIAN PUSTAKA}

\section{Konsep Pemasaran Pariwisata}

Pariwisata adalah bisnis manusia dan budaya yang memerlukan sumberdaya manusia dengan posisi, skill, dan job yang tepat. Tantangan utama pariwisata adalah pengembangan kualitas staff. Pariwisata memerlukan network (jaringan pariwisata) yang mampu menampilkan karakter zona. Dalam zona itu wisatawan bisa mobile dengan lancar dan leluasa untuk memuaskan hasrat komsumsi (Hasan, 2015).

Pentingnya pemasaran pariwisata, yaitu peningkatan pemahaman pada hakikat produk pariwisata, perkembangan pasar yang sangat dinamik menuntut strategi pemasaran yang cerdas dan bertanggung jawab kepada wisatawan, perubahan tren pemasaran global, dan otonomi daerah (Hasan, 2015).

\section{Base Oriented Social Marketing}

Pemasaran sosial adalah pemasaran yang beorientasi pada sosial yang menentukan minat pasar sasaran dan membentuk kepuasan yang lebih efektif dan efisien dibandingkan pesaing dengan cara memelihara serta meningkatkan kesejahteraan konsumen dan masyarakat dalam jangka panjang (Hasan, 2015).

\section{METODE PENELITIAN}

Penelitian ini menggunakan metode penelitian kualitatif literatur (Hamzah, 2019). Setting penelitian dilakukan di Museum Brawijaya Malang. Pengumpulan data diperoleh dari dokumentasi dan sumber-sumber tertulis baik tercetak maupun elektronik (Hamzah, 2019). 


\section{HASIL DAN PEMBAHASAN}

Sejarah adalah suatu kejadian atau peritiwa yang tak dapat terulang kembali. Oleh karena itu sejarah sangatlah perlu untuk ditulis agar dapat dipelajari dan diambil hikmahnya untuk masa depan yang lebih baik (Bintaldam, 2008).

Dewasa ini banyak irang beranggapan bahwa Museum adalah tempat atau bangunan untuk menyimpan benda-benda kuno saja. apabila memperhatikan lebih seksama, Museum bukan sekedar tempat untuk menyimpan benda-benda kuno saja, akan tetapi banyak peristiwa bersejarah yang terekam didalamnya. Dalam mengemban misi yang besar bagi pengunjung diantaranya adalah sebagai wahana yang mewariskan nilainilai kejuangan suatu bangsa, karena benda-benda koleksi Museum merupakan cermin dari kehidupan manusia pada masa lampau (Bintaldam, 2008).

Museum Brawijaya merupakan wisata yang berbasis edukasi sejarah yang menyimpan benda-benda koleksi bersejarah. Pendirian Museum Brawijaya dimaksudkan untuk membuktikan kepada masyarakat mengenal sejarah perjuangan bangsa Indonesia, khususnya rakyat Jawa Timur sejak tahun 1945 yang secara terus-menerus membuktikan dharma bhaktinya kepada ibu pertiwi (Bintaldam, 2008).

Benda koleksi Museum Brawijaya di halaman depan terdapat taman senjata yang diberi nama "Agne Yastra Loka" yang dapat diartikan sebagai tempat atau taman senjata yang diperoleh dari api revolusi 1945. Adapun benda-benda yang dipamerkan yaitu kendaraan tank, Senjata Penangkis Serangan Udara (PSU), Meriam 3,7 Inch (Si Buang), Tank Amphibi AM Track, Patung jendral Sudirman. Selain itu, terdapat dua relief. Relief sebelah selatan melukiskan wilayah kekuasaan Majapahit, juga dipahatkan perahu Hongi yang menggambarkan bahwa Majapahit memiliki armada laut yang kuat sehingga berhasil mempersatukan Nusantara serta pahatan Raden Wijaya dalam bentuk Harihara (Bintaldam, 2008).

Relief sebelah utara menunjukkan daerah-daerah tugas yang pernah dijalankan oleh pasukan-pasukan Brawijaya dalam rangka menegakkan kemerdekaan, menumpas gerakan sparatis dan gerombolan pengacau keamanan serta tugas internasional sebagai pasukan perdamaian dan keamanan PBB diluar negeri (Mesir, Kongo, Timur Tengah, Vietnam, dan sebagainya), serta terdapat Badge Kodam/Kotama TNI AD Indonesia (Bintaldam, 2008).

Pada halaman tengah Museum Brawijaya terdapat Gerbong Maut yang merupakan Gerbong barang nomor GR 10152 adalah salah satu dari 3 gerbong yang mengangkut para tawanan yang berada di penjara Bondowoso yang akan dipindahkan ke Surabaya. Gerbong Maut di Museumkan di 3 tempat, yaitu Malang, Surabaya, dan Bondowoso. Selanjutnya, Perahu Segigir yang digunakan Letkol Candra Hasan untuk memimpin pasukannya melawan Belanda. Adapun Ruang Pameran I dan Ruang Pameran II serta Perpustakaan untuk mengoleksi buku-buku dan dokumen-dokumen (Audio Visual) sejarah perjuangan TNI, karya-karya umum, dan referensi yang terkait dengan pengabdian terhadap Negara Kesatuan Republik Indonesia (Bintaldam, 2008).

Hasil literatur yang telah diuraikan mendukung teori konsep pemasaran pariwisata, yaitu peningkatan pemahaman pada hakikat produk pariwisata, perkembangan pasar yang sangat dinamik menuntut strategi pemasaran yang cerdas dan bertanggung jawab kepada wisatawan, perubahan tren pemasaran global, dan otonomi daerah (Hasan, 2015). Kegiatan yang terdapat di Museum Brawijaya dapat dikaitkan dengan pemasaran sosial. Pemasaran sosial adalah pemasaran yang beorientasi pada sosial yang menentukan kebutuhan, keinginan, dan minat pasar sasaran dan membentuk kepuasan yang lebih 

B ulletin of
$\mathbf{M}$ anagement \&
B usiness
ISSN-p:
ISSN-e:
DOI:

efektif dan efisien dibandingkan pesaing dengan cara memelihara dan meningkatkan kesejahteraan konsumen dan masyarakat dalam jangka panjang (Hasan, 2015).

\section{KESIMPULAN DAN SARAN}

Berdasarkan paparan hasil penelitian diketahui bahwa pariwisata berbasis edukasi sejarah snagatlah penting untuk dapat menumbuhkan jiwa nasionalisme, dengan cara mengenalkan produk-produk (peninggalan-peninggalan) sejarah kepada generasi muda atau generasi milenial agar dapat dipahami dan dimengerti asal muasal sejarahnya.

Di era sekarang ini perlunya peningkatan promosi melalui media sosial agar dikenal secara luas oleh masyarakat, sehingga dapat dijadikan tempat destinasi wisata sejarah yang patut di banggakan oleh masyarakat lokal maupun Indonesia.

\section{REFERENSI}

Bintaldam V Brawijaya, 2008. Sekilas Mengenal Museum Brawijaya. Buku Panduan Wisata Museum Brawijaya.

Hamzah, Amir, 2019. Metode Penelitian Kepustakaan: Kajian Filosofi, Teoritis, dan Aplikatif. Literasi Nusantara.

Hasan, Ali, 2015. Tourism Marketing. Cetakan Pertama. Yogyakarta: CAPS.

Thamrin, Kevin Akbar, 2013. Sejarah Lokal: Sejarah Kota Malang. Makalah. 